\title{
Associations and contribution of childhood diseases to fever risk among children less than five years in Uganda
}

\author{
Betty B Nambuusi ${ }^{1}$, Julius Ssempiira ${ }^{1}$, Fredrick E Makumbi ${ }^{2}$, Simon Kasasa ${ }^{2}$, Penelope Vounatsou ${ }^{3}$ \\ 1 Swiss Tropical and Public Health Institute, Basel, Switzerland; University of Basel, Basel, Switzerland; Makerere University School of Public Health, \\ New Mulago Hospital Complex, Kampala, Uganda, 2 Makerere University School of Public Health, New Mulago Hospital Complex, Kampala, Uganda, 3 \\ Swiss Tropical and Public Health Institute, Basel, Switzerland; University of Basel, Basel, Switzerland \\ Keywords: under fives, uganda, bayesian geostatistical inference, diarrhoea, ari, malaria, fever \\ https://doi.org/10.29392/001c.13072
}

\section{Journal of Global Health Reports}

Vol. 4, 2020

\begin{abstract}
Background
Despite massive investment in diseases responsible for fever among children less than five years in Uganda, the burden of the fever symptom remains high and disproportionately distributed across regions. In Uganda, studies assessing the relationship between fever prevalence and multiple childhood diseases, especially at a local scale are scanty. We analyse the 2016 Demographic and Health Survey (DHS) data to quantify the associations and contribution of childhood diseases to fever prevalence among children less than five years in Uganda at the national and regional level. Findings can lead to the development and implementation of preventive and treatment measures especially at a local scale to minimize fever-related diseases among the under-fives in Uganda.
\end{abstract}

\section{Methods}

Bayesian geostatistical logistic regression models with spatially varying coefficients were fitted to determine the associations and contribution of childhood diseases on fever prevalence at the national and regional levels. Region-specific spatially varying coefficients were modeled by a conditional autoregressive distribution. Cluster-specific random effects were introduced into the model to take into account spatial dependence in fever prevalence. Bayesian geostatistical stochastic search variable selection was applied to determine the most important predictors in explaining variation in fever prevalence. The contribution of childhood diseases to fever prevalence was estimated using population attributable fractions.

\section{Results}

The prevalence of fever was highest in Busoga and Teso regions and lowest in Bunyoro region. At the national level, the population attribution fraction of diarrhoea, acute respiratory infections (ARI) and malaria to the prevalence of fever in the under-five was 38.12 (95\% Bayesian credible intervals, BCI=25.15-41.59), 30.99 (95\% BCI=9.82-34.26) and 9.50 (95\% BCI=2.34-25.15), respectively. The attribution of diarrhoea was common in all regions except Bunyoro, while ARI was more common in Bugisu, Karamoja and West Nile, and malaria was commonest in Bunyoro. In Lango, the attribution of diarrhoea and ARI was similar.

\section{Conclusions}

Majority of fevers among the under-five are due to diarrhoea, followed by ARI. Hand washing with soap and water/detergent should be strengthened in all regions. Vaccination against ARI should be encouraged, in the regions of Central 2, Bugisu, Teso, Karamoja, Lango, West-Nile and Tooro. The health system should be reinforced to treat diarrhoea and ARI.

Fever is one of the leading causes of medical consultations in children under five years old.[@26272; 1,2 Globally, over a third of all childhood deaths are caused by feverrelated diseases. ${ }^{3}$ Similarly, in sub-Saharan Africa, fever-re- lated diseases are the leading causes of under-five deaths. ${ }^{3}$ In Uganda, malaria, diarrhoea and pneumonia have been identified as the top causes of under-five deaths. ${ }^{4,5}$ These diseases present with fever as an indication of illness in the 
early stages. ${ }^{6,7}$ Furthermore, childhood fever is the most common clinical sign of infectious diseases. It is used as a measure of the disease public health burden, and of the effectiveness of programs aimed at preventing and treating diseases. $^{8}$

World Health Organization guidelines recommend malaria testing for all patients with fever illness in areas where malaria is endemic. ${ }^{9}$ However, with the declining malaria prevalence in Uganda, ${ }^{10,11}$ many children who present with fever symptoms test negative for malaria. This implies that not all fever cases are malaria-related and other childhood infectious diseases may be responsible for other fever illness. Thus, there is need to understand the contribution of other childhood diseases to the prevalence of fever so that appropriate interventions can be implemented. The Uganda Demographic and Health Survey (DHS) is a nationally representative survey conducted every five years, to estimate among others the prevalence of fever and childhood diseases i.e, symptoms of acute respiratory infections (ARI), diarrhoea and malaria ${ }^{12}$ in children under five years. The assessment of these data enables the estimation of the proportion of childhood fevers contributed by different childhood diseases.

Although several studies have examined the causes of fever among hospital attending children in various settings, in particular those with pneumonia, ${ }^{13,14}$ gastrointestinal infections ${ }^{15,16}$ and malaria, ${ }^{17-20}$ there is scanty literature of studies estimating the contribution of different childhood diseases to the geographical distribution of fever risk in this age group. Moreover, previous studies did not consider exposure to multiple childhood diseases or confounding effects of socio-economic, interventions, health care seeking behaviour and environmental/climatic factors. Environmental factors that influence fever risk are spatially structured introducing geographical dependence on the fever burden. ${ }^{21,22}$ Studies assessing geographical variation in the relation between fever and childhood diseases are limited.

In the current study, we determine the associations of multiple childhood diseases with fever prevalence in children less than five years in Uganda at country and regional levels and quantify the contribution of childhood diseases to fever by region analyzing the 2016 DHS data and using Bayesian geostatistical models. The analysis was adjusted for spatial correlation in fever and potential confounding associations of socio-demographic characteristics, interventions (such as insecticide treated nets (ITN) use and ownership, vaccinations, treatments, health care seeking behaviour) and environmental/climatic factors. Findings of this study can aid in the planning and implementation of preventive and treatment measures, particularly at the regional scale to address fever-related diseases among the under-five children in Uganda.

\section{METHODS}

\section{COUNTRY PROFILE}

Uganda is a land locked country located in East Africa, and shares borders with South Sudan to the north, Kenya to the east, Democratic Republic of Congo to the west, and Tanza- nia and Rwanda to the south. The country lies between latitudes $1^{0}$ south and $4^{0}$ north of the equator, with altitude ranging from 620 meters to 5111 meters above sea level, and mean annual temperatures between $14{ }^{\circ} \mathrm{C}$ and $32{ }^{\circ} \mathrm{C}$. It has two rainfall seasons in a year, one during March to May and a longer season crossing from September to December. The country is divided into 116 districts grouped into 15 regions and covers an area of about 241,039 square kilometers. Uganda has a population of about 40 million people. ${ }^{23}$ It is characterized by high fertility rates (Total Fertility Rate $=5.4$ ) and a moderate life expectancy (63 years). Half of the population is younger than 15 years old while the proportion of pre-school children (aged less than 5 years) is approximately $20 \% .{ }^{23}$ Despite the moderate life expectancy for the general population, the key under-five health-related outcomes are rather poor. For example, in Uganda, the under-five mortality rate (64 deaths per 1000 live births) is still much higher than the Sustainable Development Goal target of 25 or less deaths per 1000 live births.

\section{ETHICS APPROVAL AND CONSENT TO PARTICIPATE}

In this research article, secondary data that was made available to us by the Uganda Bureau of Statistics (UBOS) and the DHS Program (www.dhsprogram.com) was used. According to survey reports, ethical approval and consent to participate was obtained by the above bodies from the Institutional Review Board of International Consulting Firm (ICF) of Calverton, Maryland, USA, and from Makerere University School of Biomedical Sciences Higher Degrees Research and Ethics committee (SBS-HDREC) and the Uganda National Council for Science and Technology (UNCST). An interview was administered only if respondents assented verbally to an informed consent statement read to them by interviewers. Verbal informed consent for each malaria test was provided by the child's parent or caregiver before the test was performed. Information on ethical approval and consent to participate is published in the 2016 DHS. ${ }^{12}$

\section{STUDY SETTING}

The study analysed data from the 2016 DHS which was carried out from June through December. ${ }^{12}$ A representative sample of 20880 households was selected according to a stratified two-stage cluster design. ${ }^{12}$ Eligible women for the interview were aged between 15 - 49 years and were either usual residents or visitors present in the selected household on the night before the survey. Out of the 19088 eligible women, the Woman's Questionnaire was successfully administered to 18506 (97\%) individuals. Disease and intervention data were collected on 15522 children under five years old.

\section{DATA}

\section{FEVER AND CHILDHOOD DISEASES}

Fever, ARI and diarrhoea data were available from the 2016 DHS questionnaires, by asking mothers whether any of their children under the age of five years had fever, cough accompanied by short, rapid breathing or had diarrhoea at any time during the two-week period preceding the survey. The 
presence of malaria was determined by a rapid diagnostic test (RDT) for children aged 6-59 months.

\section{INTERVENTIONS AND HEALTH CARE SEEKING BEHAVIOUR}

The percentages of children who received Bacillus Calmette Guerin (BCG), measles, complete Diphtheria, pertussis and tetanus (DPT) and complete polio vaccines were used as measures of vaccination coverage against the respective fever-related diseases.

ITN use and ownership were defined according to the standard guidelines of the Roll Back Malaria. ${ }^{24}$ In particular, ITN use included the percentage of people in a household that slept under an ITN, the percentage of children under 5 years in a household who slept under an ITN and the percentage of existing ITN used by the people in the household the previous night of the survey. ITN ownership comprised the percentage of households with at least one ITN, the percentage of households with at least one ITN for every two people and the percentage of the population with access to an ITN within their household.

Water, Sanitation and Hygiene (WASH) practices, specifically, the percentage of households with improved source of drinking water, improved sanitation facilities and, soap/detergent and water at hand washing places were used as preventive interventions for diarrhoea and ARI.

Health care seeking behavior was measured by the percentage of children with fever, ARI and diarrhoea for whom advice or treatment was sought from a health provider, a health facility, or a pharmacy and by the percentage of children with fever who had blood taken from a finger or heel for malaria testing. Treatments included artemisinin-based combination therapy among those who took any antimalarial drugs for fever, antibiotics in the fever cases and fluids (made from a special packet of oral rehydration salts, or government-recommended home-made) among children with diarrhoea. A list of interventions, health care seeking, and treatments measures included in the analysis is provided in Table 1.

\section{SOCIO-DEMOGRAPHIC FACTORS}

Socio-demographic characteristics included household (eg, wealth index, stool disposal, type of fuel used for cooking), maternal (e.g, age, education, marital status, occupation) and child (eg, residence, age, sex) characteristics.

\section{ENVIRONMENTAL/CLIMATIC FACTORS}

Environmental and climatic predictors were extracted from remote sensing sources. Land Surface Temperature, rainfall and Normalized Difference Vegetation Index were averaged during January to December 2016. Four land cover types were provided according to the International Global Biosphere Programme classification scheme, that is, the percentage of surface covered by forests, water and crops within a $5 \mathrm{~km}$ buffer, and area of residence (rural or urban). Distance to forests, water bodies, crops and savanna were calculated based on Moderate Resolution Imaging Spectroradiometer (MODIS) land cover satellite data of 2013. Table 2 provides a list of environmental/climatic data together with their spatio-temporal resolution and data source.

\section{BAYESIAN GEOSTATISTICAL MODELLING}

Three models were fitted to quantify the associations of childhood diseases on the presence of fever. Two Bayesian geostatistical Bernoulli regression models and a Bayesian non-spatial model. ${ }^{25}$ Both geostatistical models included spatially varying covariate associations for each childhood disease adjusted for interventions, health care seeking, treatments, socio-demographic and climatic/environmental factors as proxies of other un measured factors that may be associated with the prevalence of fever. Spatially varying associations ${ }^{26}$ were modelled at regional level using a conditional autoregressive (CAR) and exchangeable prior distributions. ${ }^{25}$ Spatial correlation was taken into account in the fever outcome by cluster-specific random associations with a multivariate normal prior distribution capturing a stationary spatial process with exponential correlation function of distance between any pair of locations. The non-spatial model contained the same variables as the CAR and exchangeable models. The deviance information criterion (DIC) was used for model comparison and a smaller DIC implied a better fitting model. ${ }^{25}$

Bayesian variable selection with stochastic search ${ }^{27}$ was performed to identify the most important predictors i.e. diseases, intervention coverage indicators, socio-economic and climatic factors related to the presence of fever and their functional form (linear or categorical). Continuous predictors were categorized according to their quartiles. Variable selection was also used to compare ITN indicators in each category of use or ownership and one or none of the indicators defining ITN use or ITN ownership was selected. The variable (none or one of the indicators in the use or ownership category) selected with the highest inclusion probability is included in the final model. For each predictor, an indicator parameter was introduced estimating the probability of inclusion of the corresponding predictor into the model. Predictors with an inclusion probability of more than $50 \%$ were considered in the final model. ${ }^{26}$ Appendix S1 in the Online Supplementary Document explains the Bayesian geostatistical modelling methodology. Parameter estimates were summarized by posterior medians and the corresponding 95\% Bayesian credible intervals (95\% BCI). Odds ratios were obtained by exponentiation of parameter estimates and they were considered statistically significant if their 95\% BCI did not include one.

The contribution of childhood diseases to the fever burden was quantified through estimating the population attributable fractions (PAF). PAF measures the percentage of all fever cases attributable to a particular disease among children less than five years. PAF can also be interpreted as the proportional reduction in fever prevalence among children less than five years that would occur if exposure to a specific disease was reduced to an alternative ideal exposure scenario. The definition of PAF was used in terms of known prevalence of the disease in the population, $p$, and the adjusted odds ratio, aOR, ${ }^{28}$ as $\left.P A F=p \frac{(a O R-1)}{(1+p(a O R-1)}\right)$. The PAFs were calculated for the whole country and for each region separately following the formula presented above. 
Table 1. Description of interventions, health care seeking and treatment coverage measures

\begin{tabular}{|c|c|}
\hline Variable & Description \\
\hline \multicolumn{2}{|l|}{ ITN ownership } \\
\hline \%hh1itn & Percentage of households with at least one ITN \\
\hline \%hh1itn4two & Percentage of households with at least one ITN for every two people \\
\hline \%pp1itn & Percentage of people with access to an ITN within their household \\
\hline \multicolumn{2}{|l|}{ ITN use } \\
\hline \%ppslept & Percentage of people in the household that slept under an ITN the previous night of the survey \\
\hline \%chslept & Percentage of children under 5 years in the household, who slept under an ITN the previous night \\
\hline \%itnused & Percentage of existing ITNs used by the people in the household the previous night \\
\hline \multicolumn{2}{|l|}{ Vaccinations } \\
\hline BCG & Percentage of children vaccinated with BCG \\
\hline DPT & Percentage of children with complete vaccination of DPT \\
\hline Polio & Percentage of children with complete vaccination of polio \\
\hline Measles & Percentage of children vaccinated against measles \\
\hline \multicolumn{2}{|c|}{ WASH practices: } \\
\hline Water & Percentage of households with improved source of drinking water \\
\hline Sanitation & Percentage of households using improved sanitation facilities \\
\hline $\begin{array}{l}\text { Soap/ } \\
\text { detergent and } \\
\text { water }\end{array}$ & Percentage of households with soap/detergent and water at hand washing place \\
\hline \multicolumn{2}{|l|}{ Treatments: } \\
\hline $\mathrm{ACT}$ & $\begin{array}{l}\text { Percentage of children receiving artemisinin-based combination therapy (ACT) among those with a fever who } \\
\text { took any antimalarial drugs (during the } 2 \text { weeks period before the survey) }\end{array}$ \\
\hline Antibiotics & Percentage of fever children receiving antibiotics \\
\hline ORS or RHF & $\begin{array}{l}\text { Percentage of children with diarrhea receiving fluid from oral rehydration solution (ORS) sachets or } \\
\text { recommended home fluids (RHF) }\end{array}$ \\
\hline \multicolumn{2}{|c|}{ Health care seeking: } \\
\hline $\begin{array}{l}\text { Rapid } \\
\text { diagnostic } \\
\text { test }\end{array}$ & Percentage of fever children who had blood taken from a finger or heel for malaria testing \\
\hline Fever advice & $\begin{array}{l}\text { Percentage of fever children for whom advice or treatment was sought from health provider, a health facility, or a } \\
\text { pharmacy }\end{array}$ \\
\hline ARI advice & $\begin{array}{l}\text { Percentage of children with symptoms of ARI for whom advice or treatment was sought from health provider, a } \\
\text { health facility, or a pharmacy }\end{array}$ \\
\hline $\begin{array}{l}\text { Diarrhoea } \\
\text { advice }\end{array}$ & $\begin{array}{l}\text { Percentage of children with diarrhea for whom advice or treatment was sought from health provider, a health } \\
\text { facility, or a pharmacy }\end{array}$ \\
\hline
\end{tabular}

\%hh1itn - Percentage of households with at least one insecticide treated net, \%hh1itn4two - Percentage of households with at least one insecticide treated net for every two people, \%pp1itn - Percentage of people with access to an insecticide treated net within their household, \%ppslept - Percentage of people in the household that slept under an insecticide treated net the previous night of the survey, \%chslept - Percentage of children under 5 years in the household, who slept under an insecticide treated net the previous night, \%itnused - Percentage of existing insecticide treated nets used by the people in the household the previous night, ITN - insecticide treated net, BCG - Bacillus Calmette Guerin, DPT - Diphtheria, pertussis and tetanus, ACT - Artemisinin-based combination therapy, ORS - Oral rehydration solution, RHF - Recommended home fluids, ARI - Acute respiratory infections

Markov Chain Monte Carlo simulation drawing samples from the posterior distribution of the OR, that is, $\mathrm{OR}^{1}, \mathrm{OR}^{2}, \ldots \mathrm{OR}^{N} \sim p(\mathrm{OR} \mid$ data $)$ were used to obtain Bayesian Credible Intervals for PAFs, with $N$ being the number of simulations. The overall mean and variance of simulated samples are estimates of the posterior mean and variance and were thus used to estimate the $95 \% \mathrm{BCI}$ for PAFs.

Descriptive data analysis was carried out in Stata, version 14.0 (Stata Corporation, College Station, TX, USA). OpenBUGS version 3.2.3 (Imperial College and Medical Research
Council, London, UK) was used to perform variable selection and model fit. Maps were produced in ArcGIS version 10.5 (ArcGIS version 10.5, Esri, Redlands, CA, USA).

\section{RESULTS \\ DESCRIPTIVE DATA ANALYSIS}

One-third (33\%) of children under the age of five (15522) had a fever in the 2 weeks preceding the survey. Of these, $47 \%$ tested positive for malaria, $34 \%$ and $18 \%$ were reported 
Table 2. Remote sensing data sources*

\begin{tabular}{llll}
\hline Source & Data type & $\begin{array}{l}\text { Temporal } \\
\text { resolution }\end{array}$ & $\begin{array}{l}\text { Spatial } \\
\text { resolution }\end{array}$ \\
\hline MODIS/Terra§ & LST¥ & 8 days & $1 \mathrm{~km}$ \\
\hline MODIS/Terra§ & NDVI¥ & 16 days & $1 \mathrm{~km}$ \\
\hline $\begin{array}{l}\text { U.S. Geological Survey-Earth Resources Observation } \\
\text { Systems (USGSS) }\end{array}$ & Rainfall & 10 days & $8 \times 8 \mathrm{~km} 2$ \\
\hline Shuttle Radar Topographic Mission (SRTM) & Altitude & NA & $1 \times 1 \mathrm{~km} 2$ \\
\hline MODIS,IBGD type & Land cover, Water & NA & $0.5 \times 0.5 \mathrm{~km} 2$ \\
\hline Global Rural and Urban Mapping project & bodies & NA & $1 \times 1 \mathrm{~km} 2$ \\
\hline
\end{tabular}

NA - Not applicable, LST - land surface temperature day and night; Land cover groups (forest, crops, urban), LST - Land surface temperature day and night, NDVI - Normalized difference vegetation index

*Land cover data accessed in June 2016 and other data accessed in November 2013.

§Moderate Resolution Imaging Spectroradiometer (MODIS)/Terra, available at: http://modis.gsfc.nasa.gov/.

Table 3. The prevalence of fever and childhood diseases at the national and regional levels, Uganda DHS 2016

\begin{tabular}{|c|c|c|c|c|}
\hline \multirow{2}{*}{ Geographical scale } & \multicolumn{4}{|c|}{ Fever and childhood disease prevalence $\mathrm{n}(\%)$} \\
\hline & Fever & Malaria & Diarrhoea & ARI \\
\hline National & $4824(33)$ & $4725(30)$ & $2832(20)$ & 1354 (9) \\
\hline \multicolumn{5}{|l|}{ Regions: } \\
\hline Kampala & $78(14)$ & $1(1)$ & $86(16)$ & $27(5)$ \\
\hline Central 1 & $459(25)$ & $93(16)$ & $359(20)$ & $147(8)$ \\
\hline Central 2 & $420(27)$ & $110(21)$ & $256(17)$ & $131(9)$ \\
\hline Busoga & $939(66)$ & $265(53)$ & $390(27)$ & $175(12)$ \\
\hline Bukedi & $345(34)$ & $90(27)$ & $182(18)$ & $50(5)$ \\
\hline Bugisu & 139 (19) & $47(20)$ & $105(14)$ & $68(9)$ \\
\hline Teso & 541 (59) & $141(52)$ & $266(29)$ & $131(14)$ \\
\hline Karamoja & $170(43)$ & $76(69)$ & $94(24)$ & 105 (27) \\
\hline Lango & 337 (44) & $170(62)$ & $157(21)$ & 135 (18) \\
\hline Acholi & 350 (49) & 154 (63) & $174(24)$ & $65(9)$ \\
\hline West Nile & $423(42)$ & $79(25)$ & 159 (16) & $78(8)$ \\
\hline Bunyoro & $96(11)$ & $87(32)$ & $85(10)$ & $8(1)$ \\
\hline Tooro & $273(24)$ & $77(18)$ & $250(22)$ & 150 (13) \\
\hline Ankole & $182(16)$ & $41(11)$ & 192 (17) & $54(5)$ \\
\hline Kigezi & $71(15)$ & $4(3)$ & $76(16)$ & $31(6)$ \\
\hline
\end{tabular}

ARI - Symptoms of acute respiratory infections

as having diarrhoea and ARI respectively. Results in Table 3 indicate that the prevalence of fever was highest among children in Busoga (66\%) and Teso (59\%) regions and lowest in Bunyoro region (11\%). Three in 10 (30\%) of under-five children tested positive for malaria according to the RDT results. The prevalence of malaria among children varies by region, from $1 \%$ in Kampala and 3\% in Kigezi regions to 69\% in Karamoja, 63\% in Acholi, and 62\% in Lango regions. Mothers reported that $20 \%$ of children under 5 years old had a diarrhoeal episode in the 2 weeks preceding the survey.
As with symptoms of fever, the percentage of children with diarrhoea was highest in Teso (29\%) and Busoga (27\%) regions and lowest in Bunyoro region (10\%). The prevalence of reported ARI symptoms was 9\%; highest among children in Karamoja region (27\%) and lowest in Bunyoro region (1\%). The varying childhood disease burden within the country may be responsible for inequalities in fever prevalence across regions in Uganda.

Table S1 in the Online Supplementary Document indicates that, among the malaria interventions, the percentage 
of households with at least one ITN has the highest coverage reaching $78 \%$ and ranges from $55 \%$ in Karamoja to 92\% in West-Nile. The percentage of households with at least one ITN for every two people is the malaria intervention with the lowest coverage of $51 \%$ varying from $23 \%$ in Karamoja to $68 \%$ in the Kigezi. Amongst vaccinations, BCG had the highest coverage (96\%) with almost all children vaccinated in all regions. The polio vaccine had the lowest coverage of $70 \%$ nationally varying from $57 \%$ in $\mathrm{Bu}-$ soga to $80 \%$ in Acholi. Overall, nearly eight out of every ten households had an improved source of drinking water, but the percentage of households having improved sanitation facilities was lower (19\%) and varied from $2 \%$ in Karamoja to $33 \%$ in Central 1.

Table S2 in the Online Supplementary Document shows that only $29 \%$ of fever children received antibiotics in Uganda. The coverage of antibiotic treatment in fever cases was highest Kampala (46\%) and in Bukedi (43\%). Countrywide, $88 \%$ of children with fever took artemisinin-combination therapy with regional variations ranging from $59 \%$ in Kigezi to $93 \%$ in Karamoja. Amongst the health care seeking behavior, the percentage of children having fever and ARI for whom advice or treatment was sought was highest (about
$80 \%)$. There were no outstanding regional differences in the coverage of both treatments.

\section{BAYESIAN GEOSTATISTICAL VARIABLE SELECTION}

Table S3 in the Online Supplementary Document contains all variables that were included in the final model with posterior inclusion probabilities of at least $50 \% .^{29}$ The inclusion probabilities of malaria, diarrhoea and ARI risks were $100 \%$, an indication of a strong relationship between fever prevalence and childhood diseases. Among preventive interventions, BCG vaccination (83\%) and the hand washing with soap/detergent and water were selected (93\%). None of the ITN interventions indicators was included in the final model due to low probabilities of inclusion, which could imply a weak relationship between ITN and fever prevalence. Socio-demographic factors including age of the child, area of residence, mothers' marital status and occupation, improved source of drinking water and household wealth index score were included in the final model with inclusion probabilities exceeding $80 \%$. 
Table 4. Posterior estimates for the associations of childhood diseases on fever prevalence adjusted for

vaccinations, socio-demographic and climatic/environmental factors (CAR, Exchangeable and non-

spatial models)

\begin{tabular}{|c|c|c|c|c|c|c|c|c|c|}
\hline \multirow{3}{*}{ Geographical scale } & \multicolumn{3}{|c|}{ CAR model } & \multicolumn{3}{|c|}{ Exchangeable model } & \multicolumn{3}{|c|}{ Non-spatial model } \\
\hline & Malaria & Diarrhoea & ARI & Malaria & Diarrhoea & ARI & Malaria & Diarrhoea & ARI \\
\hline & $\begin{array}{c}\mathrm{aOR}(95 \% \\
\mathrm{BCI})\end{array}$ & $\begin{array}{c}\mathrm{aOR}(95 \% \\
\mathrm{BCI})\end{array}$ & $\begin{array}{l}\mathrm{aOR}(95 \% \\
\mathrm{BCl})\end{array}$ & $\begin{array}{l}\mathrm{aOR}(95 \% \\
\mathrm{BCl})\end{array}$ & $\begin{array}{l}\mathrm{aOR}(95 \% \\
\mathrm{BCl})\end{array}$ & $\begin{array}{c}\mathrm{aOR}(95 \% \\
\mathrm{BCl})\end{array}$ & $\begin{array}{l}\mathrm{aOR}(95 \% \\
\mathrm{BCl})\end{array}$ & $\begin{array}{l}\mathrm{aOR}(95 \% \\
\mathrm{BCl})\end{array}$ & $\begin{array}{l}\mathrm{aOR}(95 \% \\
\mathrm{BCl})\end{array}$ \\
\hline National & $\begin{array}{c}1.35 \\
(1.08-2.12)^{*} \\
\end{array}$ & $\begin{array}{c}4.08 \\
(2.68-4.56)^{*}\end{array}$ & $\begin{array}{c}5.99 \\
(2.21-6.79)^{*} \\
\end{array}$ & $\begin{array}{c}1.69 \\
(0.87-2.98) \\
\end{array}$ & $\begin{array}{c}5.85( \\
4.75-9.41)^{*} \\
\end{array}$ & $\begin{array}{c}7.87 \\
(5.50-11.04)^{*}\end{array}$ & $\begin{array}{c}1.96 \\
(1.80-2.15)^{*}\end{array}$ & $\begin{array}{c}2.99 \\
(2.69-3.3)^{*}\end{array}$ & $\begin{array}{c}5.76 \\
(4.97-6.58)^{*}\end{array}$ \\
\hline \multicolumn{10}{|l|}{ Regions } \\
\hline Kampala & $\begin{array}{c}1.14 \\
(0.08-3.21) \\
\end{array}$ & $\begin{array}{c}1.93 \\
(1.63-2.00)^{*}\end{array}$ & $\begin{array}{c}0.74 \\
(0.25-2.13) \\
\end{array}$ & $\begin{array}{c}0.98 \\
(0.11-7.49) \\
\end{array}$ & $\begin{array}{c}2.89 \\
(0.77-5.01) \\
\end{array}$ & $\begin{array}{c}0.51 \\
(0.05-2.91) \\
\end{array}$ & & & \\
\hline Central 1 & $\begin{array}{c}0.68 \\
(0.19-2.83)\end{array}$ & $\begin{array}{c}2.72 \\
(1.88-3.74)^{*}\end{array}$ & $\begin{array}{c}0.96 \\
(0.13-2.21)\end{array}$ & $\begin{array}{c}1.01 \\
(0.39-2.82)\end{array}$ & $\begin{array}{c}3.65 \\
(1.47-4.28)^{*}\end{array}$ & $\begin{array}{c}0.50 \\
(0.14-1.54)\end{array}$ & & & \\
\hline Central 2 & $\begin{array}{c}1.48 \\
(0.69-2.43) \\
\end{array}$ & $\begin{array}{c}1.78 \\
(1.17-1.93)^{*} \\
\end{array}$ & $\begin{array}{c}1.64 \\
(1.22-3.01)^{*} \\
\end{array}$ & $\begin{array}{c}0.24 \\
(0.09-1.59) \\
\end{array}$ & $\begin{array}{c}1.70 \\
(0.65-4.19) \\
\end{array}$ & $\begin{array}{c}3.27 \\
(0.98-6.49) \\
\end{array}$ & & & \\
\hline Busoga & $\begin{array}{c}1.38 \\
(1.10-2.86)^{*} \\
\end{array}$ & $\begin{array}{c}3.21 \\
(1.18-3.77)^{*} \\
\end{array}$ & $\begin{array}{c}1.19 \\
(0.17-3.57) \\
\end{array}$ & $\begin{array}{c}2.12 \\
(1.00-4.81) \\
\end{array}$ & $\begin{array}{c}0.51 \\
(0.22-1.19) \\
\end{array}$ & $\begin{array}{c}1.11 \\
(0.42-4.27) \\
\end{array}$ & & & \\
\hline Bukedi & $\begin{array}{c}1.49 \\
(0.74-3.58) \\
\end{array}$ & $\begin{array}{c}1.74 \\
(1.14-2.54)^{*} \\
\end{array}$ & $\begin{array}{c}1.38 \\
(1.16-1.98)^{*} \\
\end{array}$ & $\begin{array}{c}2.38 \\
(0.72-6.74) \\
\end{array}$ & $\begin{array}{c}1.00 \\
(0.34-2.60) \\
\end{array}$ & $\begin{array}{c}1.14 \\
(0.37-3.42) \\
\end{array}$ & & & \\
\hline Bugisu & $\begin{array}{c}0.16 \\
(0.03-1.16) \\
\end{array}$ & $\begin{array}{c}1.29 \\
(1.03-1.64)^{*} \\
\end{array}$ & $\begin{array}{c}2.03 \\
(1.79-2.44)^{*} \\
\end{array}$ & $\begin{array}{c}0.11 \\
(0.03-1.38) \\
\end{array}$ & $\begin{array}{c}2.25 \\
(0.63-8.62) \\
\end{array}$ & $\begin{array}{c}2.36 \\
(0.72-5.36) \\
\end{array}$ & & & \\
\hline Teso & $\begin{array}{c}1.35 \\
(1.06-2.45)^{*} \\
\end{array}$ & $\begin{array}{c}3.96 \\
(1.41-5.25)^{*} \\
\end{array}$ & $\begin{array}{c}2.58 \\
(1.08-3.51)^{*}\end{array}$ & $\begin{array}{c}0.97 \\
(0.44-2.36) \\
\end{array}$ & $\begin{array}{c}0.67 \\
(0.25-1.70) \\
\end{array}$ & $\begin{array}{c}0.26 \\
(0.08-0.70)\end{array}$ & & & \\
\hline Karamoja & $\begin{array}{c}1.62 \\
(1.06-4.17)^{*} \\
\end{array}$ & $\begin{array}{c}3.61 \\
(2.06-4.51)^{*} \\
\end{array}$ & $\begin{array}{c}4.75 \\
(1.64-5.55)^{*} \\
\end{array}$ & $\begin{array}{c}1.10 \\
(0.42-2.97) \\
\end{array}$ & $\begin{array}{c}1.06 \\
(0.36-3.17) \\
\end{array}$ & $\begin{array}{c}3.11 \\
(1.26-8.82)^{*} \\
\end{array}$ & & & \\
\hline Lango & $\begin{array}{c}1.32 \\
(1.05-3.03)^{*}\end{array}$ & $\begin{array}{c}2.81 \\
(2.48-3.83)^{*} \\
\end{array}$ & $\begin{array}{c}3.26 \\
(1.07-4.68)^{*} \\
\end{array}$ & $\begin{array}{c}0.92 \\
(0.42-2.08) \\
\end{array}$ & $\begin{array}{c}0.94 \\
(0.38-2.67) \\
\end{array}$ & $\begin{array}{c}0.58 \\
(0.22-1.64) \\
\end{array}$ & & & \\
\hline Acholi & $\begin{array}{c}1.36 \\
(1.03-3.30)^{*}\end{array}$ & $\begin{array}{c}2.82 \\
(2.30-3.79)^{*} \\
\end{array}$ & $\begin{array}{c}0.62 \\
(0.08-1.95) \\
\end{array}$ & $\begin{array}{c}1.57 \\
(0.71-4.29) \\
\end{array}$ & $\begin{array}{c}3.42 \\
(1.17-8.14)^{*}\end{array}$ & $\begin{array}{c}0.41 \\
(0.10-1.37) \\
\end{array}$ & & & \\
\hline West Nile & $\begin{array}{c}1.62 \\
(0.57-2.87) \\
\end{array}$ & $\begin{array}{c}1.71 \\
(1.09-2.40)^{*} \\
\end{array}$ & $\begin{array}{c}2.94 \\
(1.96-3.43)^{*} \\
\end{array}$ & $\begin{array}{c}5.01 \\
(2.20-6.68)^{*} \\
\end{array}$ & $\begin{array}{c}0.78 \\
(0.27-2.04) \\
\end{array}$ & $\begin{array}{c}1.58 \\
(0.47-5.52) \\
\end{array}$ & & & \\
\hline Bunyoro & $\begin{array}{c}1.10 \\
(1.05-2.49)^{*}\end{array}$ & $\begin{array}{c}1.55 \\
(0.77-4.49) \\
\end{array}$ & $\begin{array}{c}0.89 \\
(0.23-1.56) \\
\end{array}$ & $\begin{array}{c}0.82 \\
(0.08-5.76) \\
\end{array}$ & $\begin{array}{c}1.51 \\
(0.22-3.26) \\
\end{array}$ & $\begin{array}{c}1.47 \\
(0.29-9.84) \\
\end{array}$ & & & \\
\hline Tooro & $\begin{array}{c}1.13 \\
(0.42-4.19) \\
\end{array}$ & $\begin{array}{c}2.38 \\
(1.55-3.33)^{*} \\
\end{array}$ & $\begin{array}{c}2.09 \\
(1.44-2.24)^{*} \\
\end{array}$ & $\begin{array}{c}1.81 \\
(0.75-4.53) \\
\end{array}$ & $\begin{array}{c}0.32 \\
(0.11-1.78) \\
\end{array}$ & $\begin{array}{c}1.25 \\
(0.51-2.95) \\
\end{array}$ & & & \\
\hline Kigezi & $\begin{array}{c}1.01 \\
(0.02-2.31) \\
\end{array}$ & $\begin{array}{c}1.45 \\
(1.01-1.56)^{*} \\
\end{array}$ & $\begin{array}{c}1.28 \\
(0.04-1.64) \\
\end{array}$ & $\begin{array}{c}0.65 \\
(0.08-4.42) \\
\end{array}$ & $\begin{array}{c}0.27 \\
(0.06-1.20) \\
\end{array}$ & $\begin{array}{c}0.69 \\
(0.10-3.68) \\
\end{array}$ & & & \\
\hline Spatial parameters & $\begin{array}{l}\text { Median (95\% } \\
\text { BCI) }\end{array}$ & $\begin{array}{l}\text { Median (95\% } \\
\text { BCI) }\end{array}$ & $\begin{array}{l}\text { Median }(95 \% \\
\text { BCI) }\end{array}$ & $\begin{array}{l}\text { Median }(95 \% \\
\mathrm{BCI})\end{array}$ & $\begin{array}{l}\text { Median (95\% } \\
\text { BCI) }\end{array}$ & $\begin{array}{l}\text { Median }(95 \% \\
\mathrm{BCI})\end{array}$ & & & \\
\hline $\begin{array}{l}\text { Regional variance of disease regression } \\
\text { coefficients }^{\ddagger}\end{array}$ & $\begin{array}{c}2.27 \\
(1.32-3.71)\end{array}$ & $\begin{array}{c}1.34 \\
(0.77-2.25)\end{array}$ & $\begin{array}{c}3.11 \\
(1.92-5.38)\end{array}$ & $\begin{array}{c}0.97 \\
(0.36-2.36)\end{array}$ & $\begin{array}{c}1.00 \\
(0.44-2.45)\end{array}$ & $\begin{array}{c}1.15 \\
(0.42-2.96)\end{array}$ & & & \\
\hline
\end{tabular}




\begin{tabular}{|c|c|c|c|c|c|c|c|c|c|}
\hline \multirow{3}{*}{ Geographical scale } & \multicolumn{3}{|c|}{ CAR model } & \multicolumn{3}{|c|}{ Exchangeable model } & \multicolumn{3}{|c|}{ Non-spatial model } \\
\hline & Malaria & Diarrhoea & ARI & Malaria & Diarrhoea & ARI & Malaria & Diarrhoea & ARI \\
\hline & $\begin{array}{l}\mathrm{aOR}(95 \% \\
\mathrm{BCI})\end{array}$ & $\begin{array}{c}\mathrm{aOR}(95 \% \\
\mathrm{BCI})\end{array}$ & $\begin{array}{c}\mathrm{aOR}(95 \% \\
\mathrm{BCI})\end{array}$ & $\begin{array}{c}\mathrm{aOR}(95 \% \\
\mathrm{BCI})\end{array}$ & $\begin{array}{c}\mathrm{aOR}(95 \% \\
\mathrm{BCI})\end{array}$ & $\begin{array}{l}\mathrm{aOR}(95 \% \\
\mathrm{BCI})\end{array}$ & $\begin{array}{c}\mathrm{aOR}(95 \% \\
\mathrm{BCI})\end{array}$ & $\begin{array}{c}\text { aOR }(95 \% \\
\text { BCI) }\end{array}$ & $\begin{array}{c}\mathrm{aOR}(95 \% \\
\mathrm{BCl})\end{array}$ \\
\hline Range $(\mathrm{km})^{\S}$ & & $2.60(1.14-7.32)$ & & & $3.09(1.00-9.6$ & & & & \\
\hline Spatial variance in fever & & $3.16(2.91-3.47)$ & & & $3.04(2.76-3.3)$ & & & & \\
\hline DIC & & 5532.0 & & & 5597.0 & & & 13770.0 & \\
\hline
\end{tabular}

aOR - adjusted odds ratio, DIC - deviation information criterion, ARI - symptoms of acute respiratory infections "Statistically significant association; aOR: adjusted odds ratio.

"Variance of conditional autoregressive process.

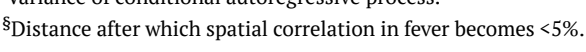


(a)

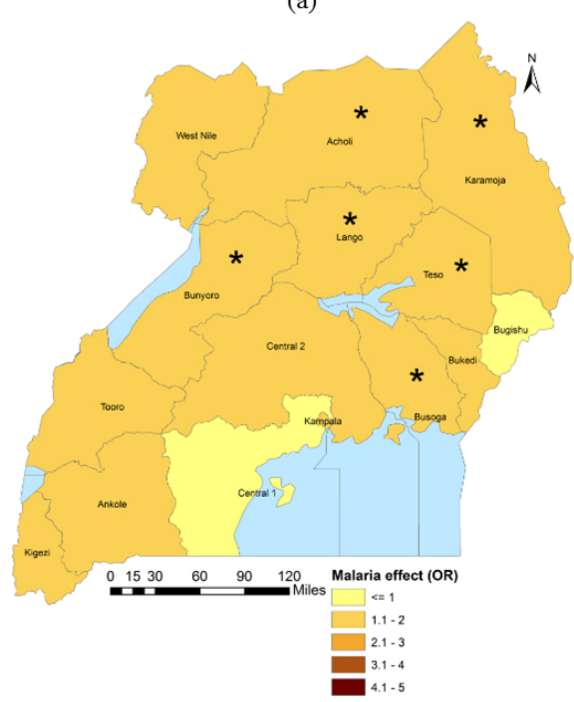

(b)

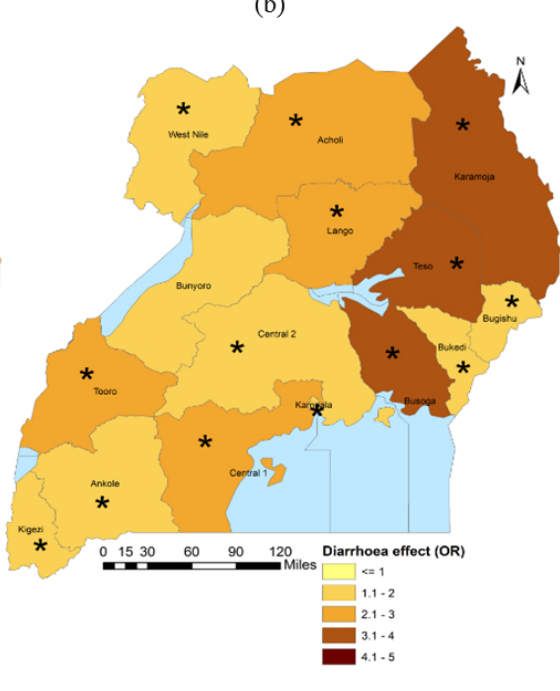

(c)

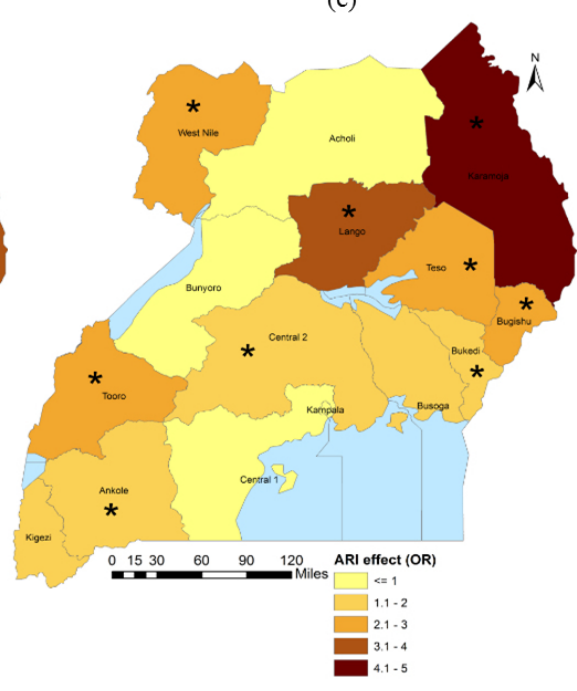

Figure 1. Geographical distribution of spatially varying disease associations on fever prevalence.

The (*) indicates a statistically significant disease association. Panels (a), (b) and (c) correspond to the associations of malaria, diarrhoea and ARI respectively on fever prevalence.

\section{ASSOCIATIONS OF CHILDHOOD DISEASES ON FEVER PREVALENCE}

Table 4 shows the associations of childhood diseases on the prevalence of fever adjusted for interventions, socio-demographic and environmental/climatic factors. Estimates of the adjusted odds ratios indicate that, after taking into account spatial correlation that was present in the fever prevalence data, the confidence intervals became wider, confirming the importance of taking spatial correlation into account when analyzing geographic data. ${ }^{30}$ Model comparison revealed that the model with the smallest DIC value (5532.0) and, therefore, with the best fit was the CAR model. All explanations of results are based on the best fitting model.

At the national level, the prevalence of malaria, diarrhoea and ARI were associated with increased odds of fever among children less than five years (Table 4). In particular, the odd of fever was $35 \%$ higher among children with malaria than children without malaria (adjusted odds ratio, $\mathrm{aOR}=1.35 ; 95 \% \mathrm{BCI}=1.08-2.12$ ). Children who experienced diarrhoeal episodes had almost four times higher odds of fever compared to children without diarrhoea $(\mathrm{aOR}=4.08$; 95\% BCI=2.68-4.56). Furthermore, the odds of fever were almost six times higher for children with ARI relative to those without ARI (aOR=5.99; 95\% BCI=2.21-6.79).

Results of spatially varying geostatistical regression (Table 4) indicate that disease associations varied by region. Figure 1 illustrates the corresponding geographical distribution.

Malaria prevalence was statistically associated with higher odds of fever in Busoga, Teso, Karamoja, Lango, Acholi and Bunyoro whereas diarrhoea increased the odds of fever in all regions except Bunyoro. ARI was associated with increased odds of fever in Central 2, Bukedi, Bugisu, Teso, Karamoja, Lango, West Nile, Tooro and Ankole regions. Spatial correlation in fever risk was rather moderate extending up to $2.60 \mathrm{~km}$ (Range=1.14-7.32).
Table 5 shows a declining trend of risk of fever with increasing coverage of vaccination. A $1 \%$ increase in the coverage of BCG vaccine was associated with a $6 \%$ reduction in the odds of fever $(\mathrm{aOR}=0.94 ; 95 \% \mathrm{BCI}=0.91-0.97)$. Children aged 12 months and older had higher odds of fever compared to those that were younger than 7 months old. The highest odds were estimated in the age of 12-23 months old $(\mathrm{aOR}=2.49 ; 95 \% \mathrm{BCI}=2.09-3.22)$. The odds of fever was lower in urban areas (aOR=0.53; 95\% BCI: 0.35-0.94), in children born to married women ( $\mathrm{aOR}=0.33$; 95\% $\mathrm{BCI}=0.25-0.45)$, in children from higher socio-economic status $(\mathrm{aOR}=0.74 ; 95 \% \mathrm{BCI}=0.66-0.91$ for the richest socioeconomic status compared to the poorest one) and, in children living in households having both water and soap/detergent at hand washing places (aOR=0.96; 95\% $\mathrm{BCI}=0.93-0.98)$. However, the odds of fever among children less than five years increase with increasing night LST $(\mathrm{aOR}=1.30$; 95\% BCI: 1.23-1.47).

\section{CONTRIBUTION OF CHILDHOOD DISEASES TO FEVER PREVALENCE}

National population attributable fraction (PAF) estimates (Table 6) indicate that $38 \% \quad(\mathrm{PAF}=38.12$; 95\% $\mathrm{BCI}=25.15-41.59), 31 \%(\mathrm{PAF}=30.99 ; 95 \% \mathrm{BCI}=9.82-34.26)$ and $10 \%(\mathrm{PAF}=9.50 ; 95 \% \mathrm{BCI}=2.34-25.15)$ of the fever burden among children less than five years in Uganda is attributable to diarrhoea, ARI and malaria respectively. Most cases of fever in Kampala, Central 1, Central 2, Busoga, Bukedi, Teso, Acholi, Tooro, Ankole and Kigezi regions are attributable to diarrhoea. In Bugisu, Karamoja and West Nile, the highest percentage of fevers can be attributed to ARI whereas in Bunyoro region, majority of the fever cases are due to malaria. In Lango, diarrhoea and ARI are equally responsible for a bigger percentage of fever cases in these regions. 
Table 5. Posterior estimates for the associations of interventions, socio-demographic and environmental/climatic factors on fever prevalence (CAR, Exchangeable and non-spatial models)

\begin{tabular}{|c|c|c|c|}
\hline \multirow[b]{2}{*}{ Variables } & CAR model & Exchangeable model & Non-spatial model \\
\hline & $\mathrm{aOR}(95 \% \mathrm{BCl})$ & aOR $(95 \% \mathrm{BCl})$ & $\mathrm{aOR}(95 \% \mathrm{BCl})$ \\
\hline \multicolumn{4}{|l|}{ Vaccinations } \\
\hline BCG & $0.94(0.91-0.97)^{*}$ & $1.00(0.97-1.08)$ & $0.95(0.91-0.96)^{*}$ \\
\hline \multicolumn{4}{|l|}{ WASH practices: } \\
\hline Water: No & 1.0 & 1.0 & 1.0 \\
\hline Yes & $0.99(0.71-1.53)$ & $1.25(0.91-1.73)$ & $0.82(0.73-0.91)^{*}$ \\
\hline Soap/detergent and water: No & 1.0 & 1.0 & 1.0 \\
\hline Yes & $0.96(0.93-0.98)^{*}$ & $0.97(0.94-0.99)^{*}$ & $0.97(0.94-0.99)^{*}$ \\
\hline \multicolumn{4}{|l|}{ Socio-demographic factors: } \\
\hline \multicolumn{4}{|l|}{ Child factors: } \\
\hline Age (months): 0-6 & 1.0 & 1.0 & 1.0 \\
\hline $7-11$ & $1.19(0.92-1.54)$ & $1.40(0.88-2.14)$ & $0.92(0.78-1.08)$ \\
\hline $12-23$ & $2.49(2.09-3.22)^{*}$ & $1.99(1.36-2.80)^{*}$ & $1.45(1.26-1.67)^{*}$ \\
\hline 24-35 & $2.06(1.89-2.62)^{*}$ & $2.64(1.86-3.83)^{*}$ & $1.34(1.14-1.54)^{*}$ \\
\hline $36-47$ & $1.62(1.22-1.91)^{*}$ & $1.53(1.10-2.11)^{*}$ & $0.93(0.81-1.06)$ \\
\hline$\geq 48$ & $1.22(1.08-1.42)^{*}$ & $2.55(1.81-3.61)^{*}$ & $1.60(1.37-1.84)^{*}$ \\
\hline Residence: Rural & 1.0 & 1.0 & 1.0 \\
\hline Urban & $0.53(0.35-0.94)^{*}$ & $0.64(0.25-1.36)$ & $0.98(0.85-1.17)$ \\
\hline \multicolumn{4}{|l|}{ Maternal factors: } \\
\hline Marital status: Not married & 1.0 & 1.0 & 1.0 \\
\hline Married & $0.33(0.25-0.45)^{*}$ & $0.32(0.24-0.43)^{*}$ & $0.49(0.43-0.55)^{*}$ \\
\hline Occupation: No & 1.0 & 1.0 & 1.0 \\
\hline Yes & $1.14(0.83-1.79)$ & $2.20(0.63-2.93)$ & $0.40(0.24-0.57)^{*}$ \\
\hline \multicolumn{4}{|l|}{ Household factors: } \\
\hline Wealth index: Poorest & 1.0 & 1.0 & 1.0 \\
\hline Poorer & $0.83(0.67-0.93)^{*}$ & $1.27(0.94-1.70)$ & $0.39(0.24-0.58)^{*}$ \\
\hline Middle & $0.73(0.53-0.86)^{*}$ & $1.29(0.92-1.75)$ & $0.69(0.51-0.94)^{*}$ \\
\hline Richer & $0.67(0.43-0.82)^{*}$ & $0.99(0.69-1.41)$ & $0.20(0.05-0.37)^{*}$ \\
\hline Richest & $0.74(0.66-0.91)^{*}$ & $1.38(0.75-2.40)$ & $0.25(0.02-0.53)^{*}$ \\
\hline Type of cooking fuel: No wood & 1.0 & 1.0 & 1.0 \\
\hline Wood & $1.06(0.43-1.23)$ & $1.19(0.86-1.75)$ & $0.98(0.84-1.14)$ \\
\hline \multicolumn{4}{|l|}{ Climatic/environmental factors: } \\
\hline$\%$ surface covered by water within a $5 \mathrm{~km}$ buffer & $0.94(0.06-1.47)$ & $0.08(0.01-1.79)$ & $0.21(0.12-1.36)$ \\
\hline LST night & $1.30(1.23-1.47)^{*}$ & $1.45(1.30-1.71)^{*}$ & $1.22(1.19-1.27)^{*}$ \\
\hline Distance to savanna & $0.90(0.72-1.09)$ & $0.83(0.69-1.02)$ & $0.90(0.8-0.92)$ \\
\hline
\end{tabular}

CAR - Conditional autoregressive, BCG - Bacillus Calmette Guerin, WASH - Water, Sanitation and Hygiene, LST - Land Surface Temperature *Statistically significant association.

\section{DISCUSSION}

With the declining prevalence of malaria in Uganda, ${ }^{11}$ there is growing awareness that most fever cases among children less than five years result from other infectious diseases, which must be identified and appropriate interventions implemented. To study this in detail, this paper quantifies the contribution of childhood diseases to the risk of fever in children below 5 years old in Uganda at the national and sub-national scale using data obtained from the 2016 DHS. Study findings indicated that most fevers among children under five years are due to diarrhoea, followed by ARI. Also, there were strong geographical variations in the associations of malaria, diarrhoea and ARI on the distribution of fever risk among children less than five years in Uganda. 
Table 6. Population attributable fraction (PAF) estimates (\%) for malaria, diarrhoea and ARI at the national and regional scale relative to fever

\begin{tabular}{|c|c|c|c|}
\hline \multirow{2}{*}{ Geographical scale } & Malaria & Diarrhoea & ARI \\
\hline & $\operatorname{PAF}(95 \% \mathrm{Cl})$ & PAF (95\% CI) & $\operatorname{PAF}(95 \% \mathrm{Cl})$ \\
\hline National & $\$ 9.50(2.34-25.15)^{*}$ & $38.12(25.15-41.59)^{*}$ & $30.99(9.82-34.26)^{*}$ \\
\hline \multicolumn{4}{|l|}{ Regions: } \\
\hline Kampala & $0.14(-0.93-2.16)$ & $12.95(9.16-13.79)^{*}$ & $-1.32(-3.90-5.35)$ \\
\hline Central 1 & $-5.40(-14.89-22.65)$ & $25.60(14.97-35.40)^{*}$ & $-0.32(-7.48-8.83)$ \\
\hline Central 2 & $9.16(-6.96-23.09)$ & $11.71(2.81-13.65)^{*}$ & $5.45(1.94-5.32)^{*}$ \\
\hline Busoga & $16.76(5.03-49.64)^{*}$ & $37.37(4.63-42.79)^{*}$ & $2.23(-11.06-23.57)$ \\
\hline Bukedi & $11.68(-7.55-41.06)$ & $11.75(2.46-21.70)^{*}$ & $1.86(0.79-4.67)^{*}$ \\
\hline Bugisu & $-20.19(-24.07-3.10)$ & $3.90(0.42-8.22)^{*}$ & $8.48(6.64-11.47)^{*}$ \\
\hline Teso & $15.40(3.03-42.99)^{*}$ & $46.19(10.63-55.21)^{*}$ & $18.11(1.11-26.00)^{*}$ \\
\hline Karamoja & $29.96(3.98-68.63)^{*}$ & $38.51\left(20.28-45.729^{*}\right.$ & $50.31(14.73-55.13)^{*}$ \\
\hline Lango & $16.56(3.01-55.72)^{*}$ & $27.54(23.71-37.28)^{*}$ & $28.92(1.24-39.85)^{*}$ \\
\hline Acholi & $18.49(1.85-59.17)^{*}$ & $30.40(23.78-40.11)^{*}$ & $-3.54(-9.03-7.88)$ \\
\hline West Nile & $13.42(-12.04-31.86)$ & $10.20(1.42-18.30)^{*}$ & $13.43(7.13-16.28)^{*}$ \\
\hline Bunyoro & $3.10(1.57-32.29)^{*}$ & $5.21(-2.35-25.87)$ & $-0.11(-0.78-0.56)$ \\
\hline Tooro & $2.29(-11.66-36.48)$ & $23.29(10.79-33.89)^{*}$ & $12.41(5.41-13.88)^{*}$ \\
\hline Ankole & $0.33(-10.45-13.10)$ & $11.17(0.51-21.80)^{*}$ & $4.03(3.80-5.03)^{*}$ \\
\hline Kigezi & $0.03(-3.03-3.78)$ & $6.72(0.16-8.22)^{*}$ & $1.65(-6.11-3.70)$ \\
\hline
\end{tabular}

PAF - population attributable fraction, CI - confidence interval

*Percentage of fever cases attributable to a disease.

\$. $50 \%$ (PAF=9.50; 95\%BCI: 2.34-25.15) of fever cases among children less than five years in Uganda are attributed to malaria, ARI - Symptoms of acute respiratory infections.

Previous studies assessed the relationship between fever risk and a single childhood disease (either malaria, diarrhoea or ARI) ${ }^{31-33}$ and did not quantify the disease contribution to fever. The current work takes into account exposure of children to multiple diseases as well as determining their contribution to fever prevalence.

Results at the national level indicated that children having malaria, diarrhoea or ARI were at a higher risk of fever compared to those without the diseases. The significant association between malaria and fever prevalence could be due to the inadequately developed immune system through the initial five years of life. ${ }^{31}$ Analysis of MIS of six African countries (Djibouti, Kenya, Namibia, Angola, Liberia and Senegal) undertaken between 2007 and 2009 found a similar result. 31

Despite the satisfactory coverage of ITN use and ownership in Uganda, ${ }^{12}$ the association between fever prevalence and ITN was not significant. This may be because the majority of fever cases are explained by diarrhoea and not malaria yet ITN target malaria-related fever. According to Atieli et al, ${ }^{34}$ Lengeler ${ }^{35}$ and Lengeler and Snow, ${ }^{36}$ households owning ITN and using them effectively, are protected from mosquito bites, thus decreasing episodes of fever or malaria infection. The least fever cases attributed to malaria may be a result of the high ITN coverage in Uganda.

The significant national association between diarrhoea and fever can be tagged to the low coverage of poor WASH practices in the country, in particular, the presence of soap/ detergent and water at hand washing places, which this study has found protective against fever. In Uganda, more than half of households lacked soap/detergent and water at hand washing places. ${ }^{12}$ In addition, only two in ten households in the country use improved toilet facilities. ${ }^{12}$ He significant association between diarrhoea and fever is distinguished. For example, Ssenyonga et al ${ }^{32}$ analysed the 2000/ 2001 Uganda DHS data and found diarrhoea to be associated with an increased risk of fever.

National estimates showed a significant association between ARI and fever prevalence despite the low ARI prevalence. A similar relationship among vulnerable age groups has been observed in other investigations such as El-Radhi et al. ${ }^{33}$ The low ARI prevalence could be attributed to the high coverage of vaccines targeting ARI conditions, particularly the pentavalent and pneumococcal vaccines. ${ }^{37}$ However, not all ARI-related fevers can be prevented through vaccination due to the presence of non-vaccine ARI serotypes, ${ }^{38}$ which calls for further efforts beyond vaccination. In order to fully address ARI in all settings, a balanced and comprehensive approach that emphasizes other preventive strategies as well as vaccination should be implemented. Uganda and other resource limited countries still have a challenge of addressing other drivers of ARI. According to Uganda's 2016 DHS, nearly thirty percent of the under-fives are stunted due to poor nutrition, which falls within the World Health Organization category of public health problems. Further, under five mortality rates are higher in 
rural areas, where almost 100 percent of households use solid type of fuel for cooking and lighting which causes air pollution and health services are severely under facilitated. ${ }^{12}$

Apart from preventive measures, the poor health system in Uganda $^{39}$ seems to contribute to the enormous disease burden in the country. Health care seeking from health facilities is high throughout the country and within regions. However, coverage of treatments is low, especially of antibiotics and ORS or RHF. Only twenty nine percent and less than half of the under-five children in Uganda having ARI and diarrhoea, respectively received treatment. ${ }^{12}$ A similar pattern prevails within regions. This may imply a weak health system in the country with lack or shortage of treatments in health facilities.

Sub-national findings showed that associations of childhood diseases on fever vary by region. This could explain the large disparities in the geographical distribution of fever prevalences within the country. The associations of malaria and ARI were highest in Karamoja while that of diarrhoea was among the strongest in this region. The statistically significant association of malaria can be attributed to the high malaria prevalence in Karamoja in which almost three quarters of children in the region tested positive with malaria. ${ }^{12}$ The high malaria burden in Karamoja has also been reported by Ssempiira et al, who analysed the Uganda MIS data 2014-15. ${ }^{40}$ The high prevalence of diarrhoea in Karamoja may be due to the deficiency of preventive interventions in this region. ${ }^{12}$ In this region, less than two in ten households had soap/detergent and water at hand washing places and only two percent of households in the region used improved sanitation facilities. ${ }^{12}$ This can explain the significant association of diarrhoea on fever in Karamoja. The high prevalence of ARI in Karamoja region ${ }^{12}$ could be responsible for the large association between ARI and fever. Besides, the high levels of poverty in this region are a contributing factor to high malaria, ARI and diarrhoea morbidity. Over eighty percent of households in Karamoja are in the lowest wealth quintile, in contrast to less than one percent in the highest quintile. The extreme poverty in this region hinders access to quality preventive health services. ${ }^{41}$ Despite the high poverty levels in Karamoja, health care seeking is satisfactory for all diseases. Treatment coverage for malaria and diarrhoea in the region is also sufficient. However, treatment for ARI in Karamoja is poor with only twenty six percent of children having ARI receiving treatment yet most fever cases in this region are attributable to ARI.

Diarrhoea risk was associated with fever prevalence in all regions except Bunyoro. This can be a result of the low implementation of WASH practices in most regions. About thirty percent of households had soap/detergent and water at handwashing places in ten out of the fifteen studied regions. ${ }^{12}$ Coverage of improved sanitation was also poor in all regions, ranging from fifteen percent to thirty three percent. ${ }^{12}$

The study revealed that ARI was significantly associated with fever prevalence in the regions of Central 2, Bukedi, Bugisu, Teso, Karamoja, Lango, West Nile, Tooro and Ankole. The smaller percentage of households having soap/ detergent and water at hand washing places may be responsible for the statistically significant associations of ARI on fever in these areas, since hand washing has been reported to lower the risk of respiratory infections. ${ }^{42}$ Only three out of ten households in over two thirds of the regions (Bugisu, Teso, Karamoja, Lango and West Nile) in which ARI had a significant association with fever had soap/detergent and water at hand washing places. ${ }^{12}$

Estimates of the population attributable fractions indicate that the highest burden of fever among children less than five years in Uganda is attributable to diarrhoea, followed by ARI and malaria had the least contribution. At the sub-national scale, most cases of fever in Kampala, Central 1, Central 2, Busoga, Bukedi, Teso, Acholi, Tooro, Ankole and Kigezi regions are attributable to diarrhoea. In Bugisu, Karamoja and West Nile, the highest percentage of fevers can be attributed to ARI whereas in Bunyoro region, majority of the fever cases are due to malaria. In Lango, diarrhoea and ARI are equally responsible for a bigger percentage of fever cases in these regions.

BCG vaccination was protective against fever. BCG is a vaccine against Tuberculosis (TB) which is known to be a fever-related disease. This relationship does not come as a surprise as vaccination against TB has been universally implemented in Uganda. Similar results have been observed in other countries. For example, an analysis of DHS data in Ghana, Nigeria, Kenya and Sierra Leon ${ }^{43}$ and a study on the global burden of fever ${ }^{44}$ reported statistically significant associations between vaccination and fever prevalence.

Children in households with higher socio-economic status had a reduced risk of fever relative to children in households with a lower status. This relationship has been found in other settings. For instance, studies by Yusuf et al. in Nigeria, ${ }^{45}$ Njau in Tanzania ${ }^{46}$ and, Novignon and Nonvignon in Ghana, Nigeria, Kenya and Sierra Leon ${ }^{43}$ found that individuals in households with better socio-economic status were less likely to report fever than those in poorer households. Wealthier households are in a better position to provide preventive and curative measures to household members including children less than five years. Rich children are less exposed to disease risk factors such as poor water, sanitation and hygiene (WASH) practices and undernutrition, because wealth people can afford such services which enhances body defenses of rich children. ${ }^{47}$ Moreover, in the case of a fever event, financial related access to right, prompt and quality health care services is easier among affluent families. In developing countries where health care costs are high, poverty could be a key hindrance to looking for early and effective treatment. 43

Children born to single mothers were at a higher risk of fever compared to those whose mothers were in union. Marital status of a woman in Africa is a proxy of improved socio-economic status, as marriage may come with advantages such as pooling of resources to support better health services and provide improved nutrition to children. ${ }^{48}$ DHS studies in Cameroon and Democratic Republic of Congo have already indicated single motherhood to be a risk factor for health outcomes of children less than five years. ${ }^{49}$

The risk of fever was higher in rural than urban areas. This may be linked to higher levels of poverty in rural areas in Uganda ${ }^{41}$ and the poorer health system where facilities often run short of medical supplies and lack skilled healthcare workers. ${ }^{47}$ Rural areas have also inadequate transport 
systems which constrain access to curative (eg, artemisinincombination therapy and antibiotics) and preventive measures of fever-related diseases (eg, insecticide treated nets and vaccinations). ${ }^{47}$ Yusuf et al. found a similar association between the risk of fever and the area of residence among children less than five years in Nigeria. ${ }^{45}$

The presence of soap/detergent and water at hand washing places was protective against the fever risk. Hand washing with a soap/detergent ensures that the transmission of germs is restricted, which substantially reduces the risk of diarrhoeal diseases among children. ${ }^{50}$ In a systematic review $^{51}$ and a study in Britain, ${ }^{52}$ handwashing with soap/detergent and water was found effective for the removal of bacteria from hands. Despite its significant association, the percentage of households with soap/detergent and water at hand washing places was low in the country with the exception of Kampala region. ${ }^{12}$

Furthermore, children aged two years and older were at a higher risk of fever compared to younger ones. This result can be attributed to the preventive effect of breastfeeding on infections in the younger group. Breastfeeding contains antibodies which reduce the risk of fever-diseases including gastroenteritis and respiratory illnesses. ${ }^{53}$ Yusuf et al., $(2010)^{45}$ also found older children to have a higher risk of fever when they analysed the Nigeria DHS 2008 data.

Environmental/climatic factors were significant predictors of fever prevalence. Increasing night LST was associated with high fever prevalence. Higher temperatures increase the rate of development of mosquitoes from one immature stage to the next. ${ }^{54}$ This accelerates vector distribution, shortens parasite life cycle, increases mosquito longevity and hence increased malaria transmission, a disease we found to be a significant driver of the fever symptom. Elevated temperatures have been reported as a risk factor of fever in other countries, for example, Thailand. ${ }^{55}$

The analysis comes with various constraints. Caretakers reported the presence of illness among under-five children in the two weeks prior to the survey. The data might have been subjected to recall bias as guardians were made to remember whether the child had illness in the previous two weeks. However, studies based on the Swedish registry data and a public health survey found high percentages of correctly self-reported data for recall periods of one month (99\%), three months (98\%), six months (96\%) and twelve months (94\%). .56 Thus, a recall period of two weeks may not result into over or under estimation of results especially when events are memorable like child health.

Another limitation of our study is that disease data for the dead children were not available and therefore we were not able to estimate the disease-related fever risk using disease information at individual level. Instead, we treated the disease prevalence at the regional level as an exposure and explained variation in fever risk within the country by the variation in the disease exposure, adjusting for birth-related factors at the individual level, maternal and household characteristics as well as coverage of interventions at regional levels. Our results are prone to the ecological fallacy; however, in the absence of individual level data, we can estimate regional disease-specific contributions or associations with fever risk. This approach can be used to estimate disease-specific contributions or associations with fever risk to monitor fever prevalence in Uganda and in other countries with sparse individual-level data.

\section{CONCLUSIONS}

In Uganda, the majority of fevers among children under five years are due to diarrhoea, followed by ARI. Therefore, improved coverage of diarrhoea and ARI interventions in the country while prioritizing the affected regions may be essential in minimizing fever-related morbidity. In particular, hand washing with soap/detergent and water should be strengthened in all regions except Bunyoro. Vaccination against ARI should be encouraged, especially, in the regions of Central 2, Bukedi, Bugisu, Teso, Karamoja, Lango, WestNile, Tooro and Ankole. The health system should be reinforced to treat diarrhoea and ARI mainly in the affected areas.

Acknowledgement: We thank the Uganda Bureau of Statistics and DHS MEASURE for making the data available.

Funding: This research was supported by the Swiss Programme for Research on Global Issues for Development project (Grant number: IZ01Z0-147286) and the European Research Council advanced grant project (Grant number: 323180).

Authorship contributions: All authors take responsibility for the structure and content of the paper. BBN conceptualized the research, managed and analyzed the data, developed the methodology and implemented it in software, interpreted results and wrote the first draft of the manuscript. Author JS participated in data management. Authors FEM and SK formulated research goals and objectives, participated in the process of acquisition of project financial support and edited the manuscript. PV was the lead author who conceived the research, formulated research goals and objectives, acquired project financial support, led methodology development, model fitting and result interpretation and manuscript writing.

Competing interests: The authors have completed the ICMJE COI form (available upon request from the corresponding author) and declare no conflicts of interest.

\section{Correspondence to:}

Penelope Vounatsou, PD, PhD

Swiss Tropical and Public Health Institute

Socinstrasse 57

P.O. Box CH-4002

Basel

Switzerland

penelope.vounatsou@swisstph.ch 
This is an open-access article distributed under the terms of the Creative Commons Attribution 4.0 International License (CCBY-4.0). View this license's legal deed at http://creativecommons.org/licenses/by/4.0 and legal code at http://creativecommons.org/licenses/by/4.0/legalcode for more information. 


\section{REFERENCES}

1. Royal College of Obstetricians and Gynaecologists. Feverish Illness in Children: Assessment and Initial Management in Children Younger than 5 Years. London: Royal College of Obstetricians and Gynaecologists; 2013.

2. Nnedu ON, Rimel B, Terry C, Jalloh-Vos H, Baryon B, Bausch DG. Syndromic diagnosis of malaria in rural Sierra Leone and proposed additions to the national integrated management of childhood illness guidelines for fever. Am J Trop Med Hyg. 2010;82:525-528. doi:10.4269/ajtmh.2010.09-0188

3. Liu L, Oza S, Hogan D, Chu Y, Perin J, Zhu J, et al. Global, regional, and national causes of under-5 mortality in 2000-15: An updated systematic analysis with implications for the Sustainable Development Goals. Lancet. 2016;388:3027-3035. doi:10.1016/S014 $\underline{0-6736(16) 31593-8}$

\section{Ministry of Health. Annual Health Sector Performance Report for Financial Year 2015/2016. Kampala, Uganda: Ministry of Health; 2015.}

5. Nabongo P, Verver S, Nangobi E, Mutunzi R, Wajja A, Mayanja-Kizza H, et al. Two year mortality and associated factors in a cohort of children from rural Uganda. BMC Public Health. 2014;14:314. doi:10.118 6/1471-2458-14-314

6. Armon K, Stephenson T, Gabriel V, MacFaul R, Eccleston P, Werneke U, et al. Determining the common medical presenting problems to an accident and emergency department. Arch Dis Childhood. 2001;84:390-392. doi:10.1136/adc.84.5.390

7. Finkelstein JA, Christiansen CL, Platt R. Fever in pediatric primary care: Occurrence, management, and outcomes. Pediatrics. 2000;105:260-266.

8. Olotu A, Fegan G, Williams TN, et al. Defining clinical malaria: The specificity and incidence of endpoints from active and passive surveillance of children in rural Kenya. Snounou G, ed. PLOS ONE. 2010;5(12):e15569. doi:10.1371/journal.pone.001556 $\underline{9}$

9. World Health Organization. Guidelines for the Treatment of Malaria. Third edition. Geneva: World Health Organization; 2015.

10. Uganda Bureau of Statistics (UBOS), ICF Macro. Uganda Malaria Indicator Survey 2009. Calverton, Maryland, USA: UBOS and ICF Macro; 2010.
11. Uganda Bureau of Statistics (UBOS), ICF International. Uganda Malaria Indicator Survey 2014-15. Kampala, Uganda, and Rockville, Maryland , USA: UBOS and ICF International; 2015.

12. Uganda Bureau ofStatistics (UBOS), ICF. Uganda Demographic and Health Survey 2016. Kampala, Uganda and Rockville, Maryland, USA: UBOS and ICF International; 2018.

13. Stein RT, Marostica PJC. Community-Acquired pneumonia: A review and recent advances. Pediatric Pulmonology. 2007;42:1095-1103. doi:10.1002/ppul.2 $\underline{0652}$

14. Lutfiyya M, Henley E, Chang L, Reyburn S. Diagnosis and treatment of community-acquired pneumonia. American Family Physician. 2006;73:442-450.

15. Nguyen TV, Le Van P, Le Huy C, Weintraub A. Diarrhea Caused by Rotavirus in Children Less than 5 Years of Age in Hanoi, Vietnam. Journal of Clinical Microbiology. 2004;42(12):5745-5750. doi:10.1128/jc m.42.12.5745-5750.2004

16. Nitiema LW, Nordgren J, Ouermi D, Dianou D, Traore AS, Svensson L, et al. Burden of rotavirus and other enteropathogens among children with diarrhea in Burkina Faso. Int J Infecti Dis. 2011;15:e646-652. d oi:10.1016/i.ijid.2011.05.009

17. Lubanga RGN, Norman S, Ewbank D, Karamagi C. Maternal diagnosis and treatment of children's fever in an endemic malaria zone of Uganda: Implications for the malaria control programme. Acta Tropica. 1997;68:53-64. doi:10.1016/S0001-706X(97)00071-5

18. D’Acremont V, Kilowoko M, Kyungu E, Philipina S, Sangu W, Kahama-Maro J, et al. Beyond malaria Causes of fever in outpatient Tanzanian children. $N$ Engl J Med. 2014;370:809-817. doi:10.1056/NEJMoa12 14482

19. Elfving K, Shakely D, Andersson M, Baltzell K, Ali AS, Bachelard M, et al. Acute uncomplicated febrile illness in children aged 2-59 months in Zanzibar Aetiologies, antibiotic treatment and outcome. PLOS ONE. 2016;11:e0146054. doi:10.1371/journal.pone.01 $\underline{46054}$

20. Uzochukwu BSC, Onwujekwe EO, Onoka CA, Ughasoro MD. Rural-Urban Differences in Maternal Responses to Childhood Fever in South East Nigeria. Keiser J, ed. PLOS ONE. 2008;3(3):e1788. doi:10.1371/ journal.pone.0001788 
21. Siraj AS, Santos-Vega M, Bouma MJ, Yadeta D, Carrascal DR, Pascual M. Altitudinal Changes in Malaria Incidence in Highlands of Ethiopia and Colombia. Science. 2014;343:1154-1158. doi:10.1126/ science. 1244325

22. Ssempiira J, Nambuusi B, Kissa J, et al. Geostatistical modelling of malaria indicator survey data to assess the effects of interventions on the geographical distribution of malaria prevalence in children less than 5 years in Uganda. Braga ÉM, ed. PLOS ONE. 2017;12(4):e0174948. doi:10.1371/journa l.pone. 0174948

23. Uganda Bureau of Statistics. The National Population and Housing Census 2014 - Main Report. Kampala, Uganda: Uganda Bureau of Statistics; 2016.

24. World Health Organisation. Household Survey Indicators for Malaria Control. Geneva: World Health Organisation; 2013.

25. Banerjee S, Gelfand A, Carlin B. Hierarchical Modeling and Analysis for Spatial Data: Monographs on Statistics and Applied Probability. 2nd ed. New York: Chapman \& Hall/CRC; 2015.

26. Giardina KS, Sié A, Utzinger J, Tanner M, Vounatsou P. Associations of vector-control interventions on changes in risk of malaria parasitaemia in sub-Saharan Africa: A spatial and temporal analysis. Lancet Glob Health. 2014;2:e601-615. doi:10.1016/S2214-109X(14)7030 $\underline{0-6}$

27. George MRE. Variable selection via Gibbs sampling. Journal of the American Statistical Association. 1993;88:881-889. doi:10.1080/0162145 9.1993.10476353

28. Leviton A. Definitions of attributable risk. Am J Epidemiol. 1973;98:231-231. doi:10.1093/oxfordjourn als.aje.a121552

29. Barbieri MM, Berger JO. Optimal predictive model selection. Annals of Statistics. 2004;32:870-897. doi:1 $\underline{0.1214 / 009053604000000238}$

30. Okiro EA, Snow RW. The relationship between reported fever and Plasmodium falciparum infection in African children. Malar J. 2010;9:99. doi:10.1186/1 475-2875-9-99

31. Ssenyonga R, Muwonge R, Twebaze F, Mutyabule R. Determinants of acute diarrhoea in children aged 0 - 5 years in Uganda. East African Medical Journal. 2009;86:513-519.

32. El-Radhi AS, Barry W, Patel S. Association of fever and severe clinical course in bronchiolitis. Arch Dise Child. 1999;81:231-234. doi:10.1136/adc.81.3.231
33. Atieli HE, Zhou G, Afrane Y, et al. Insecticidetreated net (ITN) ownership, usage, and malaria transmission in the highlands of western Kenya. Parasites Vectors. 2011;4(1). doi:10.1186/1756-330 5-4-113

34. Lengeler C. Insecticide-treated bed nets and curtains for preventing malaria. Cochrane Database Syst Rev. 2004;2:CD000363. doi:10.1002/14651858.C D000363.pub2

35. Lengeler C, Snow RW. From efficacy to effectiveness: Insecticide-treated bednets in Africa. Bull World Health Organ. 1996;74:325-332.

36. Gavi Full Country Evaluations Tea. CrossCountry: Findings from the 2015 Gavi Full Country Evaluations. Seattle, WA: IHME; 2016.

37. Schaad UB. Prevention of paediatric respiratory tract infections: Emphasis on the role of OM-85. European Respiratory Review. 2005;14:74-77. doi:10.1 $\underline{183 / 09059180.05 .00009506}$

38. Ssempiira J, Kasirye I, Kissa J, Nambuusi B, Mukooyo E, Opigo J, et al. Measuring health facility readiness and its associations on severe malaria outcomes in Uganda. Sci Rep. 2018;8:17928. doi:10.10 38/s41598-018-36249-8

39. Ssempiira J, Nambuusi B, Kissa J, et al. Geostatistical modelling of malaria indicator survey data to assess the effects of interventions on the geographical distribution of malaria prevalence in children less than 5 years in Uganda. Braga ÉM, ed. PLOS ONE. 2017;12(4):e0174948. doi:10.1371/journa l.pone. 0174948

40. Yeka A, Gasasira A, Mpimbaza A, Achan J, Nankabirwa J, Nsobya S, et al. Malaria in Uganda: Challenges to control on the long road to elimination. Acta Tropica. 2012;121:184-195. doi:10.1016/j.actatro pica.2011.03.004

41. Rabie T, Curtis V. Handwashing and risk of respiratory infections: A quantitative systematic review. Trop Med Int Health. 2006;11:258-267. doi:1 0.1111/j.1365-3156.2006.01568.X

42. Novignon J, Nonvignon J. Socioeconomic status and the prevalence of fever in children under age five: Evidence from four sub-Saharan African countries. BMC Res Notes. 2012;5. doi:10.1186/1756-0500-5-38 $\underline{0}$

43. Kothari A, Pruth A, Chugh T. The burden of enteric fever. J Infect Developing Countries. 2008;2:253-225. 
44. Yusuf B, Adeoye B, Oladepo OO, Peters DH, Bishai D. Poverty and fever vulnerability in Nigeria: A multilevel analysis. Malar J. 2010;9(235). doi:10.1186/ 1475-2875-9-235

45. Njau JD, Goodman C, Kachur SP, Palmer N, Khatib RA, Abdulla S, et al. Fever treatment and household wealth: The challenge posed for rolling out combination therapy for malaria. Trop Med Int Health. 2006;11:299-313. doi:10.1111/i.1365-3156.20 06.01569.x

46. Victora WA, Schellenberg JA, Gwatkin D, Claeson M, Habicht J-P. Child survival IV: Applying an equity lens to child health and mortality: More of the same is not enough. Lancet. 2003;362:233-241. doi:10.101 6/S0140-6736(03)13917-7

47. Kanmiki EW, Bawah AA, Agorinya I, Achana FS, Awoonor-williams JK, Oduro AR, et al. Socioeconomic and demographic determinants of underfive mortality in rural northern Ghana. BMC Int Health Hum Rights. 2014;14:24. doi:10.1186/1472-69 8X-14-24

48. Ntoimo LF, Odimegwu CO. Health associations of single motherhood on children in sub-Saharan Africa: A cross-sectional study. BMC Public Health. 2014;14. doi:10.1186/1471-2458-14-1145

49. Ejemot-Nwadiaro RI, Ehiri JE, Meremikwu MM, Critchley JA. Hand washing for preventing diarrhoea. Ejemot-Nwadiaro RI, ed. Cochrane Database of Systematic Reviews. January 2008. doi:10.1002/14651 858.cd004265.pub2
50. Curtis V, Cairncross S. Effect of washing hands with soap on diarrhoea risk in the community: A systematic review. Lancet Infect Dis. 2003;3:275-281. doi:10.1016/S1473-3099(03)00606-6

51. Burton M, Cobb E, Donachie P, Judah G, Curtis V, Schmidt W-P. The effect of handwashing with water or soap on bacterial contamination of hands. Int J Environ Res Public Health. 2011;8:97-104. doi:10.339 0/ijerph8010097

52. Anatolitou F. Human milk benefits and breastfeeding. Journal of Pediatric and Neonatal Individualized Medicine. 2012;1:11-18.

53. Machault V, Vignolles C, Borchi F, Vounatsou P, Pages F, Briolant S, et al. The use of remotely sensed environmental data in the study of malaria. Geospat Health. 2011;5:151-168. doi:10.4081/gh.2011.167

54. Nitatpattana N, Singhasiwanon P, Kiyoshi H, Andrianasolo H, Yoksan S, Gonzalez J-P, et al. Potential association of dengue hemorrhagic fever incidence and remote senses land surface temperature, Thailand, 1998. Southeast Asian J Trop Med Public Health. 2007;38:1-7.

55. Kjellsson G, Clarke P, Gerdtham U-G. Forgetting to remember or remembering to forget: A study of the recall period length in health care survey questions. $J$ Health Econ. 2014;35:34-46.

56. Kjellsson G, Clarke P, Gerdtham U-G. Forgetting to remember or remembering to forget: A study of the recall period length in health care survey questions. Journal of Health Economics. 2014;35:34-46. doi:10.1 016/j.jhealeco.2014.01.007 


\section{SUPPLEMENTARY MATERIALS}

\section{Online Supplementary Document}

Download: https://www.joghr.org/article/13072-associations-and-contribution-of-childhood-diseases-to-fever-riskamong-children-less-than-five-years-in-uganda/attachment/35617.pdf 